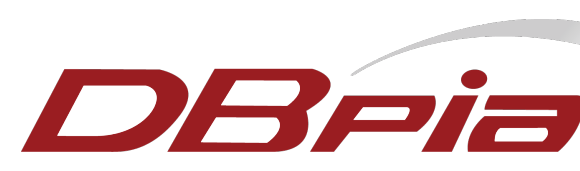

Assessment of pain and adequacy of pain management in hospitalized cancer patients

저자

(Authors)

출처

(Source)

발행처

(Publisher)

URL

APA Style

이용정보

(Accessed)
Yeonghee Shin

Journal of Korean Academy of Nursing 29(5), 1999.10, 1113-1122 (10 pages)

한국간호과학회

Korean Society of Nursing Science

http://www.dbpia.co.kr/Article/NODE02026396

Yeonghee Shin (1999). Assessment of pain and adequacy of pain management in hospitalized cancer patients. Journal of Korean Academy of Nursing, 29(5), 1113-1122.

계명대학교

114.71.5.212

2016/01/08 11:28 (KST)

\title{
저작권 안내
}

DBpia에서 제공되는 모든 저작물의 저작권은 원저작자에게 있으며, 누리미디어는 각 저작물의 내용을 보증하거나 책임을 지지 않습니다.

이 자료를 원저작자와의 협의 없이 무단게재 할 경우, 저작권법 및 관련법령에 따라 민, 형사상의 책임을 질 수 있습니다.

\section{Copyright Information}

The copyright of all works provided by DBpia belongs to the original author(s). Nurimedia is not responsible for contents of each work. Nor does it guarantee the contents.

You might take civil and criminal liabilities according to copyright and other relevant laws if you publish the contents without consultation with the original author(s). 


\title{
Assessment of pain and adequacy of pain management in hospitalized cancer patients*
}

\author{
Yeonghee Shin
}

\begin{abstract}
The author investigated pain experiences of 90 cancer patients and the adequacy of pain treatment they have received during their stay at a large medical center in $\mathrm{T}$ city between October 1994 and August 1995. Pain was assessed by the Shortened $\mathrm{BPQ}$ and results are summarized as follows: As for ratings of "worst pain" during the 24 hour period. $70 \%$ of the patients reported they had "severe" pain. As for ratings on "pain now," $43 \%$ of the cancer patients reported "moderate to severe" pain. Over $46 \%$ of the patients reported a pain relief score of 0 (not at all) or 1 (somewhat) even after receiving pain medication.

Adequacy of analgesic treatment was evaluated by comparing the patient's reported level of pain and the analgesic use, namely, the pain management index(PMI). The PMI indicated that 58\% of the patients were undertreated for the pain control. In review of nurse's notes, systematic pain assessment was scarcely recorded, although pain documentation appeared in $70 \%$ of the notes: and the contents were mostly simple description. In conclusion, the results of patient's pain ratings, the PMI and poor pain documentation in the nurse's notes implied poor pain assessment and management.
\end{abstract}

\section{INTRODUCTION}

Pain is one of the most frequent and disturbing symptoms of cancer patients (Daut \& Cleeland. 1982). According to the World Health Organization(WHO)'s estimation. 3.5 million people in the world suffer unrelieved cancer pain each day (quoted in Haviley, et al. 1992). Bonica(1990). after reviewing 54 papers from 15 different countries, summarized that nearly $50 \%$ of the hospitalized cancer patients or $70 \%$ of the terminal cancer patients were apparently suffering from severe pain. Cancer pain originates from more than one source. but in the most of the cases the pain can be controlled by relatively simple measures (Management of cancer pain guideline panel. 1994). In many countries, pain relief and palliative care have been given low priority in oncological care. Reasons for this may be multiple: (1) a focus on cure rather than care, (2) stoic attitudes of both patients and care-givers to pain. and (3) general fear of opioid addiction that contributed to policies on opioid imports. manufacture, distribution. and

\footnotetext{
* The study was supported by the Bisa Research Grant of Keimyung University in 1994.

' RN. PhD. Assistant professor. College of Nursing Kemiyung University. Taegu. Korea.
} 
prescription. Most of all, undertreatment of cancer pain is attributable to clinicians' inadequate assessment and management practices (Camp, 1988: Charap. 1978: Management cancer pain guideline panel, 1994: Park \& Shin. 1994).

The assessment of pain is a prerequisite to effective pain management. Better understanding of the extent of pain in cancer may lead to improved ability to manage it(Daut. Cleeland \& Flanery, 1983). In spite of the importance of the study of pain in cancer, few data concerning the frequency and severity of pain are available. In Korea, work by Choi, Sook-Kyung (1997). Han, Ji-Youn, et al(1996). Lee, Doo-Ik(1992), Chung, Bok-Yae(1989) and the present work have provided some information about assessment and management of pain in cancer patients. Lack of a reliable, valid and easily administered measure of pain may have accounted, in part, the scarcity of investigations on this important topic.

The most commonly employed pain assessment scales are: The simple descriptive scale(SDS), the visual analog scale(VAS), and numeric rating scale(NRS) (Management of cancer pain guideline panel, 1994). In the pain assessment processes the single most important step is the patient's self-report, either verbal or written (Camp, 1988). Another important step is the communication about the pain between the patient and the caregiver. Many assessment scales may be academically accurate and detailed but. often too difficult or too lengthy for both to patients and caregivers. In that sense, Brief Pain Questionnaire(BPQ) developed by Daut, Cleeland \& Flanery(1983) seems best suited in clinical settings in its brevity, simplicity and easiness of administra-tion.

The aim of this study was (1) to examine the level of pain severity of cancer patients and (2) to examine the adequacy of pain management of the cancer patients in the context of the World Health Organization's (WHO) 3-level ladder(WHO, 1996).

\section{LITERATURE REVIEW}

The World Health Organization (WHO) estimates that 3.5 million people in the world suffer unrelieved cancer pain each day (quoted in Haviley, et al, 1992). According to several authors(Bonica, 1990: Cleeland, 1985 :Donovan. Dillon \& McGuire, 1987: Han, et al, 1996), it is estimated that $30-50 \%$ of patients with early to intermediate disease and $55-75 \%$ who are in the terminal phases experience pain. Further. the pain has been classified as severe or excruciating in $30 \%$ of the cases and moderate to severe in $60 \%$. The consequences of inadequate pain management include suffering. anxiety. fear, depression, anger, inmobility, and isolation, leading to a decreased quality of life. In approximately $90 \%$ of patients, cancer pain can be controlled through relatively simple means(Schug. Zech, \& Dorr, 1990: Teoh \& Stjernsward, 1992), yet undertreatment of cancer pain is a serious and neglected public health problem (National Cancer Institute, 1990). The challenge to health care professionals is to identify those patients in need. to evaluate their pain. and to administer appropriate measures to manage it.

Effective pain management must be individualized according to the patient's needs. According to the AHCPR's mangement of cancer pain guidelines(1994). the simplest dosage schedules and least invasive pain management modalities should be used first. Convenient, cost-effective oral administration is preferred. Analgesic treatment of mild to moderate cancer pain should include an NSAID or acetaminophen, unless there is a contraindication. When pain persists or increases, an opioid such as codein or hydrocodone should be added. For persistent or moderate to severe pain, higher doses or an opioid of greater potency can be given. Doses can be given around-the-clock with additional "rescue" doses as needed, Regularly dosing maintains a 
constant level of drug in the body and helps to prevent a recurrence of pain.

Assessment of pain in the cancer patient is imperative for all health care professionals because failure to assess pain can lead to its undertreatment. The critical role of the assessment of cancer pain was highlighted in a 1993 study of 897 oncologists who, collectively in the previous 6 months, had managed more than 70.000 cancer patients(quoted in Management of cancer pain guideline panel. 1994). According to these physicians, poor pain assessment was the greatest barrier to effective cancer pain management in their own practices(Von Roenn. Cleeland. Gonin. Hatfield. \& Pandya, 1993).

Pain is what the patient says it is and not what the health care provider expects it to be or thinks it ought to be. Thus patient's selfreport is the single most reliable indicator of pain. One of the most commonly used pain assessment instrument is the Brief Pain Inventory (or Brief Pain Questionnaire) which was developed specifically for cancer patients and measures relevant aspects of pain. namely history, intensity, location and interference with activities. A comprehensive assessment is, of course, not possible with such a brief instrument. The $B P Q$ is a compromise between investigator's desire to assess as much as possible and the limits imposed by the clinical settings, and it is characterized by brevity. clarity and self-administration(Daut. Cleeland \& Flanery. 1983). Since its introduction. the $\mathrm{BPQ}$ has been translated into 7 languages(Cleeland, 1990: Romero, Plancarte, Heidrich, \& Cleeland, 1991: Larue, Colleau, Brasseur. \& Cleeland, 1995) and been applied to the clinical assessment of pain or epidemiological research. The author used shortened $\mathrm{BPQ}$ in this work.

\section{METHODS}

\section{Study sample}

A total of 90 hospitalized patients with cancer at a large tertiary care hospital in $\mathrm{T}$ city during the period of October, 1994 and August, 1995. The study included only patients 18 years or older who were able to communicate, and excluded patients with severe physical disability. mental confusion or delirium. Approval for this study was obtained from the department of nursing administration of the hospital where data collection was carried out. The purpose of the study was described to the subjects and they were guaranteed that the individual's response would remain anonymous. After receiving consent for participation. the author read the questionnaire for patients and recorded patient's responses. There were several reasons for choosing this approach. Many of the subjects were either aged with low educational background or suffering from pain too severe to allow them to read and answer the questionnaires by themselves. General characteristics and medical information of the study sample are presented in Table 1.

\section{Instrument}

The Shortened Brief Pain Questionnaire $(S B P Q)$. Originally the $B P Q$, a self-report instrument designed to assess the multidimensional nature of pain, was used to assess the intensity of pain and the extent to which pain interferes with life activities(Daut. Cleeland. \& Flanery. 1983). The BPQ is a reliable and valid measure of pain (Daut. Cleeland. \& Flanery, 1983), it has been selected by Cancer Unit of the WHO to monitor the effectiveness of cancer pain relief programs. For pain intensity, there are four variables "pain worst", "pain least." "pain average," and "pain now." each with a range of $0-10$. Based on the fact that many 
patients lacked understanding with the 0-10 response system and the original $\mathrm{BPQ}$ is not brief enough for clinical use for cancer patients. The 0-4 response system contained essential part of original scale and patients have had little difficulty in understanding. The author also excluded 7 interference items about a patient's life caused by pain because patients complained of their abstractness. This short form of the $\mathrm{BPQ}$ included a representation of the human figure and asked questions about worst. least. average and present pain over the past 24 hours on a scale of 0 to 4 instead of 0 to 10 . Each scale was presented as a horizontal row of equidistant numbers from 0 to 4 , and was bounded by the words "no pain" at the 0 end and "pain as bad as you can imagine" at the other. The patients were also asked to estimate the degree of pain relief they were receiving from their pain treatment and to locate areas of pain on a human figure. Reliability of the scale was 0.89 , demonstrating the good internal consistency of the scale.

Adequacy of analgesics prescription. Pain management can be thought of as adequate when there is congruence between the patient's reported level of pain and the analgesic he/she is using. The WHO guideline(1996) recommends that cancer patients with mild pain should be receiving at least a nonsteroidal analgesic (such as acetaminophen), patients with moderate pain should be receiving at least a less-potent opioid (such as codeine), and that patients with severe pain should be receiving an analgesic of the morphine type. The Pain Management Index(PMI) provides a comparison of the most potent analgesic prescribed for a patient relative to the level of that patient's reported pain. To construct the index, the 4 levels of analgesic drug therapy used were determined by the potency: (0) no order for analgesic. (1) nonopioid(e.g., NSAIDS or acetaminophen). (2) weak opioid(e.g., codeine), and (3) strong opioid(e.g., morphine). Potency of anaigesic was then compared with "pain worst." on this shortened BPQ. Pain scores of 0 were coded as 0 (no pain): scores of 1 were coded as 1(mild pain): scores of 2 were coded as 2(moderate pain): and scores of 3-4 were coded as 3 (severe pain). The PMI is computed by subtracting the pain level from the analgesic level. It ranges in value from -3 (a patients with severe pain receiving no analgesic drugs) to +3 (the patients receiving morphine or an equivalent, and reporting no pain). Negative PMI scores are considered to indicate undermedication and scores of 0 or greater are considered to indicate acceptable treatment.

Chart review. After an interview with patients. the author recorded data from a chart review including patient's diagnosis, types of treatment. physician's prescription of analgesics, route of administration, and frequency of administration.

A questionnaire was used to assess age. gender, level of education, and other demographic variables

\section{Statistical Analysis}

Data were analyzed using SPSS/PC (version 9) statistics software through the generation of standard descriptive statistics and t-tests and correlations. Frequencies and percentages were calculated for ratings of worst, least, average pain and pain now. t-Tests and correlations were calculated to analyze the relationship between pain intensity and patients demographic variables. In order to determine the adequacy of analgesic treatment of the cancer patients, the PMI was computed.

\section{Results}

\section{Patient characteristics}

The mean age of the 90 patients included in this study was 56.5 years. $59 \%$ of them were 
male and $88 \%$ were married. The patients varied widely with respect to their primary cancer diagnosis. The most common primary cancer site included stomach $(31.1 \%)$, lung and intrathoracic $(16.8 \%)$. breast $(12.2 \%)$, and colorectal $(11.1 \%)$. The average length of period since diagnosis of the cancer was 11.7 months(SD 20.4: range 1-144 months). About $46 \%$ of the subjects had received surgical therapy and $21.1 \%$ of them had received chemotherapy. Additional patient demographic data are provided in Table 1.

\section{<Table 1> Patient characteristics}

\begin{tabular}{|c|c|}
\hline & $(\mathrm{N}=90)$ \\
\hline Categories & $\mathrm{n}(\%)$ \\
\hline \multicolumn{2}{|l|}{ Gender } \\
\hline male & $53(58.9)$ \\
\hline female & $37(41.1)$ \\
\hline \multicolumn{2}{|l|}{ Marital status } \\
\hline Married & $79(87.8)$ \\
\hline Widowed & $9(10.0)$ \\
\hline Never married & $2(2.2)$ \\
\hline \multicolumn{2}{|l|}{ Education } \\
\hline No education & $17(18.9)$ \\
\hline Elementary & $32(35.6)$ \\
\hline Junior & $21(23.3)$ \\
\hline Senior & $16(17.8)$ \\
\hline College \& above & $3(3.3)$ \\
\hline No response & $1(1.1)$ \\
\hline \multicolumn{2}{|l|}{ Occupation } \\
\hline Laborer/Farmer & $32(35.5)$ \\
\hline Self-employed & $12(13.3)$ \\
\hline Office worker & $9(10.0)$ \\
\hline Other & $5(5.6)$ \\
\hline Unemployed & $32(35.6)$ \\
\hline \multicolumn{2}{|l|}{ Monthly income } \\
\hline$\leq 1,000,000$ won & $48(53.3)$ \\
\hline$>1.000 .000$ won & $27(30.0)$ \\
\hline No response & $15(16.7)$ \\
\hline \multicolumn{2}{|l|}{ Primary diagnosis } \\
\hline Stomach & $28(31.1)$ \\
\hline
\end{tabular}

\section{$<$ Table is continued}

\begin{tabular}{lr}
\hline Categories & $\mathrm{n}(\%)$ \\
\hline Lung \& intrathoracis & $16(17.8)$ \\
Breast & $11(12.2)$ \\
Colorectal & $10(11.1)$ \\
Liver & $9(10.0)$ \\
Cervical & $5(5.6)$ \\
Pancreatic & $4(4.4)$ \\
Other & $7(7.8)$ \\
Cancer treatment & \\
Surgery & $41(45.6)$ \\
Chemotherapy & $19(21.1)$ \\
Radiation & $5(5.6)$ \\
Combined treatment & $17(18.8)$ \\
None & $8(8.8)$ \\
Age* & $56.5( \pm 11.14)$ \\
Illness duration* & \\
Months & $11.7( \pm 20.4)$ \\
Range & $1-144$ \\
\hline
\end{tabular}

* Mean and standard deviation

2. Sites of pain

All 90 patients reported that they needed pain treatment at some point during their hospital stay and most of them experienced pain in the abdominal, back and chest regions and had multiple pains (Table 2).

$<$ Table $2>$ Sites of pain

\begin{tabular}{lr} 
& $(\mathrm{N}=90)$ \\
\hline Sites & $\mathrm{n}(\%)$ \\
\hline Head. neck & $5(3.4)$ \\
Breast. thoracic region & $25(16.9)$ \\
Upper shoulder. upper limbs & $11(7.4)$ \\
Abdominal region & $61(41.2)$ \\
Lower back. lumbar spine & $28(18.9)$ \\
Lower limbs & $9(6.1)$ \\
Anal. perianal. genital region & $7(4.7)$ \\
Everywhere & $2(1.4)$ \\
\hline
\end{tabular}


$<$ Table 3> Pain intensity on each of four scales

$(\mathrm{N}=90)$

\begin{tabular}{lccccc}
\hline scale & No pain & Mild & Moderate & Severe & Intolerable \\
& $\mathrm{n}(\%)$ & $\mathrm{n}(\%)$ & $\mathrm{n}(\%)$ & $\mathrm{n}(\%)$ & $\mathrm{n}(\%)$ \\
\hline Worst pain* & - & $6(6.7)$ & $21(23.3)$ & $27(30.0)$ & $36(40.0)$ \\
Least pain* & $18(20.0)$ & $48(53.3)$ & $16(17.8)$ & $8(8.9)$ & \\
Average pain* & $2(2.2)$ & $25(27.8)$ & $44(48.9)$ & $18(20.0)$ & $1(1.1)$ \\
Present pain** & $10(11.1)$ & $37(41.1)$ & $27(30.0)$ & $12(13.3)$ & $4(4.4)$ \\
\hline
\end{tabular}

* Pain experience during the past 24 hour period

** Pain experience at the moment of the interview

\section{Pain intensity}

Pain intensity during the last 24 hours was rated on a scale of $0-4$ (with 0 being no pain and 4 being intolerable pain). The percentages of patient ratings on each of four scales are reported in Table 3 . Seventy percent $(70.0 \%)$ of the patients reported a "worst pain" intensity score of 3 (severe) or greater, $26.7 \%$ reported a "least pain" intensity score of 2 (moderate) or greater(severe), and 70\% reported "average pain" intensity score of 2 (moderate) or greater(severe). About ninety percent $(88.8 \%)$ of patients were in pain at the time of interview and over $47 \%$ of the patients had a current intensity score of 2 (moderate) or greater (severe).

Bivariate relationships between each of the four pain intensity measures and demographic variables were examined. Pearson product moment correlations revealed that patient perception of their disease severity was positively correlated with worst pain scores $(r=.372$. $p=.002)$ and with average pain scores $(r=.294$, $p=.014)$. This indicates that pain scores become greater as patients perceive their disease to be more severe. Other demographic variables such as age, gender, education, and monthly income were not significantly correlated with pain scores.

\section{Pain relief after pain medication}

Pain relief following the administration of the analgesic was evaluated using a 4 point Likert scale(with 0 being no pain relief at all and 3 being complete pain relief). The mean pain relief score following administration of a pain medication was 1.62 (range $0-3, \mathrm{SD}=.88$, $\mathrm{N}=69$ ), which corresponded to "somewhat or moderate" relief. However, over $46 \%$ of the patients reported a pain relief score of 0 (not at all) or 1 (somewhat) even after receiving pain medication.

\section{$<$ Table 4 > Pain relief after pain medication}

\begin{tabular}{lc} 
& $(\mathrm{N}=69)$ \\
\hline Categories & $\mathrm{n}(\%)$ \\
\hline No relief & $6(8.7)$ \\
Some relief & $26(37.7)$ \\
Moderate relief & $25(36.2)$ \\
Complete relief & $12(17.4)$ \\
\hline
\end{tabular}

Note. Out of 90 , only 69 patients responded

\section{Pain management index}

In order to determine the adequacy of analgesic management of cancer patients, the pain management index(PMI) was computed. Consistent with the finding of a high percentage of patients with severe pain, $58 \%$ of the patients in this sample had a negative PMI, indicating that the prescribed treatment was inadequate by WHO pain management standards. Table 5 represents the percentage of patients with each PMI score from this study. Previous studies have identified potential 
predictors of inadequate pain management such as age and gender (Cleeland et al, 1994). In this study, however, a logistic regression analysis failed to identify these predictors of poor pain management

$<$ Table 5> Pain Management index

\begin{tabular}{rr} 
& $(\mathrm{N}=81)$ \\
\hline PMI & $\mathrm{n}(\%)$ \\
\hline-3 & $1(1.2)$ \\
-2 & $32(39.5)$ \\
0 & $14(17.3)$ \\
1 & $29(35.8)$ \\
2 & $3(3.7)$ \\
\hline
\end{tabular}

Note. Eighty one patients with analgesic prescription records reported.

As seen in Table 6, when individual analgesic orders were examined, of 90 patients, 12 received no pain medication at all; 43 received NSAIDs: 2 received weak opioids: and 33 received strong opioids. These drugs are used alone or in combination to manage pain. The majority of analgesics were given parentally $(70 \%)$ and only $39.5 \%$ received at least one pain medication around the clock. while $60.5 \%$ were given analgesics on an "as needed (prn)" basis. Other pain treatments, such as TENS or a nerve blocker, were hardly used.

\section{$<$ Table 6s Type of analgesic prescriptions}

\begin{tabular}{lr} 
& $(\mathrm{N}=90)$ \\
\hline Analgesics & $\mathrm{n}(\%)$ \\
\hline None & $12(13.3)$ \\
Only NSAIDs & $43(47.8)$ \\
Weak opioids+ NSAIDs & $2(2.2)$ \\
Strong opioids+NSAIDs & $33(36.7)$ \\
\hline
\end{tabular}

\section{Nurse's pain record}

Examination of the nurse's notes for 90 patients revealed that 64 of them contained documentation of patients pain: however, they did not represent pain assessment, rather a simple description of patient's complaints. The frequency of documentation of patient pain by a nurse was on an average of 1.4 times per patient during his/her hospital stay.

\section{DISCUSSION}

The short version of $B P Q$ was administered to 90 cancer patients to evaluate pain intensity and pain management effectiveness. The short form of BPQ was found to be a simple and valid alternative to other more sophisticated scales. The reliability of the scale was appropriate for this study.

Results of this study concur with previous studies that inadequate pain management remains a significant problem. Unfortunately. $84.4 \%$ of the patients stated that they were in pain at the time of interview, a far greater number than the $43 \%$ reported by Donovan. Dillon. \& McGuire in 1987.

When examining data were collapsed into mild-moderate-severe categories, $70 \%$ of the patients reported that they had severe pain (worst pain coded as 3 or 4 on a $0-4$ Likert scale). As a way of comparison. the author compared this percentage with those obtained from other cancer pain surveys, including studies from United States as well as Korea. It appeared that a higher proportion of patients are in severe pain than those in earlier study samples in the United States(Marks \& Sachar, 1973: Cohen, 1980: Donovan, Dillon, \& McGuire, 1987), but was similar to those of Han, et al(1996), Lee, Doo Ik(1992), Chung. Bok Yae(1989) in Korea. This is consistent with patient's report of poor pain relief and about $2 / 3$ of sample had a negative PMI score. The author of this study suggested that ongoing method of pain assessment and evaluation might aid in correcting some of the deficiencies in pain management observed in 
this investigation.

According to patient reports, $46 \%$ of them did not get pain relief following analgesic medication and chart review showed that $58 \%$ of the patients were receiving less than adequate pain management, indicating undertreatment of pain. When comparing this result with similar studies carried out in other countries, more patients in this study were found to be inadequately managed than those in the US $(42 \%)$ (Cleeland. et al. 1994) and France (51\%) (Larue, Colleau. Brasseur, \& Cleeland, 1995). However, patients of this study may have better analgesic treatment than those in China $(67 \%$ )(Wang. Mendoza. Gao, \& Cleeland, 1996) or India (79\%) (Saxena, Mendoza, \& Cleeland. 1999).

The most common analgesic drugs used in this study were NSAIDs (e.g., valentac, tarasin) and strong opioids(e.g., morphine, demerol, M-S contine. fentanyl). It was this investigator's assessment that patients receive analgesic drugs less than optimum level. The vast majority of analgesic medications were given parentally. Despite of WHO's recommendation, the use of oral analgesics was surprisingly low, Over onehalf of pain medications were given on "prn" basis. This is surprising since accepted criteria for chronic pain management suggest the most appropriate regimens include scheduled analgesics to provide around-the-clock relief of pain and "prn" medications to address breakthrough pain(Inturrisi, 1989).

Nurse's notes were very discouraging in that pain assessment and documentation was scarce and inconsistent. Similar result has been reported by Lee, McPherson, and Zuckman (1992). Health care professionals should ask about pain regularly, because recent studies have shown that patients are reluctant to volunteer information about pain(von Roenn. Cleeland, Gonin, Hatfield, \& Pandya, 1993).

The assessment of the patient's pain and of the efficacy of the treatment plan should be ongoing, and the details of the assessment should be documented.

Although generalization is not possible from this small study sample, however several factors may account for this inadequate cancer pain management. Health care professionals may have been trained to be concerned about addiction, tolerance development to analgesics, sideeffect management problem, and governmental scrutiny of professionals who prescribe or handle narcotics. Pain management for cancer patients may have a low priority in cancer care education. Most of all, communication gap between patients and caregivers may have been the barrier to the effective pain management.

This study suggested that most (86.7\%) patients had analgesic prescription, and the majority of these medications were ordered on an "as needed" basis. One of the major principles, advocated in both the American Pain Society Guide (American Pain Society, 1992) and the Agency for Health Care Policy and Research (AHCPR) Clinical Practice Guideline (Management cancer pain guideline panel. 1994), is that pain medications should be given on a routine basis to prevent pain rather than to treat pain because prevention of pain is easier to achieve than attempting to relieve pain after it occurs.

Experts in Korea and abroad suggested a need to educate patients and caregivers to enhance the opportunities to communicate among them and to modify routine practice patterns(Kim. SJ et al, 1997: American Pain Society Quality of Care Committee, 1995). This author concurs with those expert opinions.

\section{CONCLUSION}

The author conducted a survey utilizing the shortened $B P Q$ to evaluate the adequacy of pain management in 90 cancer patients admitted to a large medical center in $T$ city and obtained following results:

1. Seventy percent $(70 \%)$ of the patients under 
analgesic medication reported severe pain experience during the last 24 hour period.

2. Over $47 \%$ of the patients had moderate to severe pain at the time of interview.

3. Only $13.3 \%$ of the patients reported complete pain relief after pain medication. and over $46 \%$ of the patients felt that they are not receiving sufficient pain relief through their medication.

4. Fifty eight percent $(58 \%)$ of the patients had a negative PMI, indicating they were inadequately treated for their pain.

5. Analgesics were mostly prescribed on "prn" basis and most frequent route of administration was parenteral.

6. Nurses documented patients pain in $70 \%$ of nurse's notes examined: however, the content of the documentation was frequently incomplete.

In conclusion, the results of this study showed that level of pain management appears to be inconsistent with accepted pain management standard. This is at least in part attributed to the lack of pain assessment.

\section{REFERENCES}

American Pain Society(1992). Principles of analgesic use in the treatment of acute pain and cancer pain. Skokie, IL.

American Pain Society Quality of Care Committee(1995). Quality improvement guidelines for the treatment of acute pain and cancer pain. JAMA, 274, 1874-1880.

Bonica, J. J.(1990). Cancer pain: current status and future needs. In $\mathrm{JJ}$ Bonica(Ed.). The management of pain (2nd ed) (pp. 400-445). Philadelphia: Lea \& Febiger.

Camp, L. D. (1988), A comparison of nurses' recorded assessments of pain with perceptions of pain as described by cancer patients. Cancer Nursing. 11(4). 237-243.

Charap, A. D.(1978). The knowledge, attitudes and experience of medical personnel treating pain in the terminally ill. Mt Sinai J Med(NY), 45. 561-580.

Choi, S. K.(1997). Pain mangement in terminal cancer patient admitted to hospice ward. Unpublished master's thesis, Catholic University. Seoul. Korea.

Chung. B. Y.(1989). Characteristics of pain reaction in patients with cancer, Kyungpook University Medical Journal. J. 30(2), 174181.

Cleeland. C. S.(1985). Measurement and prevalence of cancer pain. Semin Oncol Nurs, 1. 87-92.

Cleeland, C. S.(1990). Assessment of pain in cancer. In: KM Foly, JJ Bonica. V Ventafridda, MV Callaway(Eds.). Advances in pain research and therapy (pp. 47-55), 16 . New York: Raven

Cleeland, C. S., Gonin, R. Hatfield, A. K., Edmonson. J. H.. Blum. R. H.. Stewart. J. A. \& Pandya. K. J.(1994). Pain and its treatment in outpatients with metastatic cancer. New England Journal Medicine, 330, 592-596.

Cleeland, C. S.. Nakamura. Y.. Mendoza. T. R. Edwards, K. R., Douglas, J.. \& Serlin, R, C.(1996). Dimensions of the impact of cancer in four country sample: new information from multidimensional scaling. Pain. 67, 267273.

Cohen, F.(1980). Postsurgical pain relief: Patients ${ }^{\circ}$ status and nurses medication choices. Pain. 9, 265-274.

Daut. R. L.. \& Cleeland. C. S.(1982). The prevalence and severity of pain in cancer. Cancer, 50, 1913-1918.

Daut, R. L., \& Cleeland. C. S. \& Flanery. R.C.(1983). Development of the Wisconsin Brief Pain Questionnaire to assess pain in cancer and other diseases. Pain, 17, 197-210.

Donovan, M.. Dillon, P. \& McGuire. L.(1987). Incidence and characteristics of pain in a sample of medical surgical inpatients. Pain. 30, 69-78. 
Han, J.. Kim. J., Kang, J., Hyung, M. H., Hong. Y.. Kim, H., Lee, K., Lim. D. Yeoun, G.. Kim, Y. O., Seo, I. O., Chong. Y., Cho, Y. Choe. S. Y.. Kim. J. Y.. \& Heo J. H.(1996). Pain control in the terminal cancer patients at hospice-ward. Journal of Korean Cancer Association, 28(2), 295-300.

Haviley, C., Gagnon, J., MacLean, R., Renz, J., Jones, O., De Witt, W., Nyberg. K., Burns, C., \& Pohl. D. (1992). Pharmacological manage-ment of cancer pain. Cancer Nursing, 15(5), 331-346.

Inturrisi, C. E.(1989). Management of cancer pain: Pharmacology and principles of management. Cancer, 63, 2308-2320.

Kim, S. J.. Hong. S. H., Sung, L. N.. Kim, E. S., Hong. E. H.. Yeum, M. R., Lee, E. H., Woo, K. S., Yoo, K. S., Yoo, Y. M., \& Lee, E. O.(1997). Effects of a systematic pain management method used by a group of nurses on pain management of oncology patients. The Journal of Korean Academic Society of Adult Nursing. 9(1), 148-161.

Larue, F.. Colleau, S. M., Brasseur, L., \& Cleeland, C. S.(1995). Multicentre study of pain and its treatment in France. British Medical Journal, 310(6986), 1034-1037.

Lee, D. I.(1992). The management of pain in cancer patients, Kyung-Hee Medical Journal, 8(2), 97-104.

Lee, S. D.. McPherson, M. I., Zuckman, I. H.(1992). Quality assessment: Documentation of pain assessment in hospice patients. American Journal of Hospice Palliative Care. $\mathrm{Jan} / \mathrm{Feb}, 38-43$.

Management of cancer pain guideline panel (1994). Management of cancer pain. clinical practice guideline no. 9. AHCPR publication no. 94-0592. Rockville, MD: Agency for Health Care Policy and Research, US. Department of Health and Human Services. Public Helath Service.

Marks, R. M., Sachar, E. J.(1973). Undertreatment of medical inpatients with narcotic analgesics. Annals Internal Medicine. 78. 173-181.

National Cancer Institute(Sept 14-15, 1990). NCI workshop on cancer pain. Bethesda, MD.

Park, Y. S.. \& S.. Y.(1994). Nurses' knowledge on pain management. The Journal of Korean Academic Society of Adult Nursing. 12. 299-307.

Romero, J., Plancarte, R., Heidrich. G.. \& Cleeland. C. S.(1991). First time opioid use for the control of cancer pain in a previously opioid naive population: a comparison of two samples. American Pain Society 10th Annual Scientific meeting. New Orleans, Louisiana.

Saxena, A.. Mendoza, T., \& Cleeland, C. S. (1999). The Assessment of Cancer Pain in North India: the validation of the Hindi Brief Pain Inventory-BPI-H. Journal of Pain Symptom Manage, 17(1), 27-41.

Schug, S.A., Zech, D., Dorr, U.(1990). Cancer pain management according to WHO analgesic guidelines. Journal of Pain Symptom Manage. 5(1), 27-32.

Von Roenn, J. H., Cleeland, C. S., Gonin, R., Hatfield, A. K., \& Pandya. K. J.(1993). Physician attitudes and practice in cancer pain management: a survey from the Eastern Cooperative Oncology Group. Ann \& of Internal Medicine, 119(2), 121-126.

Teoh, N., \& Stjernsward, J.(1992). WHO cancer pain relief program-ten years on. Seattle: International Association for the Study of Pain. International Association of Study of Pain Newsletter, 5-6.

Wang, X. S., Mendoza, T. R., Gao, S. Z., \& Cleeland, C.S.(1996). The Chinese version of the Brief Pain Inventory(BPI-C): its development and use in a study of cancer pain. Pain, 67, 407-416.

World Health Organization(1996). Cancer pain relief: with a guide to opioid availability (2nd ed). Geneva: WHO. 